\title{
Possíveis fontes e processos magmáticos evolutivos do Granito Chasqueiro, SE do Cinturão Dom Feliciano, Brasil
}

\author{
Daniel T. VIEIRA', Edinei KOESTER², Rodrigo Chaves RAMOS ${ }^{3}$ \& Cristine LENZ ${ }^{4}$
}
${ }^{1}$ Engenharia Geológica, Centro de Engenharias, Universidade Federal de Pelotas. Rua Gomes Carneiro, 02, CEP 96010-610, Pelotas, RS, Brasil (daniel.vieira@ufpel.edu.br).
2 Departamento de Geologia, Universidade Federal do Rio Grande do Sul. Caixa Postal 15001, CEP 91.501- 970, Porto Alegre, RS, Brasil (koester@ufrgs.br).
3 Secretaria de Meio Ambiente e Preservação Ecológica, Prefeitura Municipal de Sapiranga. Av. João Corrêa, 808, CEP 93.800-222, Sapiranga, Brasil (rodrigoramos@sapiranga.rs.gov.br).
4 Departamento de Geologia, Universidade Federal de Sergipe. Av. Marechal Rondon, S/N, CEP 49100-000, São Cristóvão, SE, Brasil (crislenz@yahoo.com.br).

\begin{abstract}
Resumo. Este trabalho apresenta novas constatações sobre a evolução do Granito Chasqueiro, uma das principais ocorrências de rochas graníticas cálcico-alcalinas alto-K no Cinturão Dom Feliciano, no extremo sul do Brasil. O objetivo deste trabalho é discutir as principais fontes e processos magmáticos envolvidos na evolução deste granito durante o Ediacarano (574 $\mathrm{Ma}$ ), com base em novos dados de geoquímica isotópica (Sr-Nd, rocha total) em amostras representativas do granito e dos enclaves dioríticos associados. O granito mostra razões ${ }^{87} \mathrm{Sr} /{ }^{86} \mathrm{Sr}_{(t)}$ intermediárias (0,7095-0,7139), $\varepsilon \mathrm{Nd}_{(t)}$ negativo $\left(-0,36\right.$ a -2,94) e $\mathrm{T}_{\mathrm{DM}}$ entre 1,06 e 1,18 Ga. A amostra de enclave máfico apresenta razões ${ }^{87} \mathrm{Sr}^{86} \mathrm{Sr}_{(t)}=0,74672$, mais elevadas que aquelas do granito, $\varepsilon \mathrm{Nd}_{(t)}$ negativo $(-1,63)$ e $\mathrm{T}_{\mathrm{DM}}$ de 1,15 $\mathrm{Ga}$. Com base nos dados de isótopos apresentados neste estudo, juntamente com dados geoquímicos de rocha total compilados de trabalhos anteriores, sugerimos que os principais processos de evolução magmática do Granito Chasqueiro são: (i) processo de cristalização fracionada, marcado por concentrações e depleções expressivas em Ba, Sr, P, Nb, Ti, e Eu, que reforçam a extensa cristalização fracionada dos líquidos primários; (ii) mistura de magmas, onde cada magmatismo (máfico e félsico) possui fontes e processos evolutivos diferentes e (iii) retrabalhamento crustal das rochas máficas e gnaisses do embasamento regional $\left(\varepsilon \mathrm{Nd}_{(t)}\right.$ negativo). Como resultado destes processos, 0 Granito Chasqueiro é altamente diferenciado, com composições semelhantes a granitos Tipo-I.

Palavras-chave. Petrologia; Geoquímica isotópica Sr-Nd; Mistura de Magmas; Retrabalhamento Crustal; Cristalização Fracionada
\end{abstract}

Abstract. POSSIBLE SOURCES AND MAGMATIC PROCESSES OF THE CHASQUEIRO GRANITE, SE DOM FELICIANO BELT, BRAZIL. This paper presents new constraints on the evolution of the Chasqueiro Granite, which represents one of the main occurrences of high-K, calc-alkaline granitic rocks in the Southernmost Dom Feliciano Belt, Brazil. The main goal of this work is to discuss the main sources and magmatic processes for this magmatism and implications for the evolution of the granite during the Ediacaran (574 Ma), based on new isotope geochemistry (whole-rock $\mathrm{Sr}-\mathrm{Nd}$ ) from representative samples of the granite and associated dioritic enclaves. The Chasqueiro Granite yields intermediate ${ }^{87} \mathrm{Sr} /{ }^{86} \mathrm{Sr}_{(i)}$ ratios $(0.7095-0.7139)$, negative $\varepsilon \mathrm{Nd}_{(\mathrm{t})}(-0.36$ to -2.94) and $\mathrm{T}_{\mathrm{DM}}$ between 1.06 and $1.18 \mathrm{Ga}$. The mafic enclave sample yields higher initial ${ }^{87} \mathrm{Sr}^{86} \mathrm{Sr}_{(\mathrm{i})}$ ratios $=0.74672$, negative $\varepsilon \mathrm{Nd}_{(t)}(-1.63)$, and $\mathrm{T}_{\mathrm{DM}}$ of $1.15 \mathrm{Ga}$. Based on the isotope data presented in this study, together with compiled whole rock geochemical data from previous works, we suggest that the main processes involved in the magmatic evolution of the Chasqueiro Granite are: (i) fractional crystallization processes, marked by significant depletion of $\mathrm{Ba}, \mathrm{Sr}, \mathrm{P}, \mathrm{Nb}, \mathrm{Ti}$, and Eu, strengthening the fractional crystallization hypothesis for the primary liquids; (ii) magma mixing, in which both mafic and felsic magmatism derived from distinct sources and processes and (iii) crustal reworking of mafic rocks and gneisses from the regional metamorphic basement (negative $\varepsilon N d_{(t)}$ ). As result of such processes, the Chasqueiro Granite represents a strongly differentiated granite, with compositions similar to those of I-Type granites.

Keywords. Petrology; Sr-Nd Isotopes; Magma Mixing; Crustal Reworking; Fractional Crystallization 


\section{Introdução}

As rochas graníticas correspondem, em grande parte, aos produtos magmáticos finais da diferenciação crustal, constituindo um componente importante na produção da crosta continental na Terra (Condie et al., 2009; Condie \& Aster, 2010). A extração do magma, do local de geração até sua colocação em níveis mais rasos, gerando crostas graníticas, representa o principal processo de diferenciação da crosta continental (Brown, 2013).

No setor sul do Cinturão Dom Feliciano, extremo sul do Brasil, relacionado à amalgamação do paleocontinente Gondwana Ocidental, rochas graníticas cálcicas-alcalinas alto-K são amplamente distribuídas (Philipp, 1998; Vieira et al., 2016; Cruz, 2019; Silva et al., 2020). Esses granitoides podem fornecer importantes informações sobre as características do crescimento e retrabalhamento crustal durante a última orogênese que afetou essa região.

No Domínio Sudeste do Cinturão Dom Feliciano (Ramos et al., 2014; Silveira et al., 2020), um dos principais granitoides cálcico-alcalinos alto-K ocorre próximo da cidade de Arroio Grande- RS, denominado de Granito Chasqueiro (Philipp, 1998; Philipp et al., 2002; Vieira et al., 2016; Cruz, 2019). Este granito é interpretado como um produto de um evento magmático em um regime descompressivo, pós-colisional, associado ao sistema de zonas de cisalhamento dúcteis transcorrentes Ayrosa Galvão-Arroio Grande (Philipp, 1998; Philipp et al., 2002; Vieira et al., 2016; Vieira et al., 2019a).

O presente trabalho apresenta novos dados isotópicos Sr-Nd (rocha total), além de uma reavaliação dos dados geoquímicos disponíveis para o Granito Chasqueiro, com o objetivo de investigar as possíveis fontes e processos magmáticos que atuaram durante a sua evolução. Adicionalmente, busca-se uma melhor compreensão da evolução do magmatismo cálcico-alcalino alto-K associado a zonas de cisalhamento regionais, ativas ou reativadas durante os estágios finais da amalgamação do paleocontinente Gondwana Ocidental durante o ciclo orogênico Brasiliano-Pan-africano.

\section{Contexto geológico}

O Granito Chasqueiro está localizado na zona rural de Arroio Grande, estado do Rio Grande do Sul (Fig. 1A e 1B). Essa região está localizada no extremo sul da porção brasileira do Cinturão Dom Feliciano, faixa móvel que se estende desde o leste do estado de Santa Catarina até o extremo sudeste do Uruguai, representando o setor meridional da Província Mantiqueira (Almeida et al., 1981; Silva et al., 2005a). Essa província, juntamente com sua contraparte africana (Orógeno Damara, no oeste da Namíbia - e.g., Gray et al., 2008), está relacionada à configuração do paleocontinente Gondwana Ocidental durante o ciclo orogênico Brasiliano-Pan-africano (e.g., Gaucher et al., 2009; Siegesmund et al., 2018).

No Escudo Sul-rio-grandense, o Cinturão Dom Feliciano é subdividido em quatro domínios geofísicos principais (Fernandes et al., 1995a, 1995b; Costa, 1997; Ramos et al., 2014), englobando associações petrotectônicas brasiliano-pan-africanas distintas: Domínio Oeste (Terreno São Gabriel - e.g., Hartmann et al., 2007), Domínio Central (Terreno Tijucas e Bacia do Camaquã - e.g., Chemale et al., 1995), Domínio Leste (Terreno Cuchilla Dionisio-Pelotas - e.g., Fragoso-César et al., 1986; Philipp, 1998; Bossi \& Gaucher, 2004), e Domínio Sudeste (Terreno Punta del Este, sensu Ramos et al., 2020) (Fig. 1).

Esses domínios, com distintas evoluções crustais, refletem a complexa história geológica do Cinturão Dom Feliciano, que pode ser dividida em três estágios orogênicos principais (Babinski et al., 1997; Silva et al., 2005b; Saalmann et al., 2011; Brito-Neves et al., 2014; Hueck et al., 2018; Ramos et al., 2020): (i) Brasiliano I, com clímax em ca. 780-680 Ma, relacionado às orogenias São Gabriel (Domínio Oeste) e Piratini (Domínio Leste) e ao fechamento do paleo-oceano Charrua; (ii) Brasiliano II, com clímax em ca. 640-620 Ma, relacionado à orogenia Dom Feliciano nos domínios Central, Leste e Sudeste, representado por intenso magmatismo continental e retrabalhamento crustal, e o fechamento do paleo-oceano Adamastor; (iii) Brasiliano III, entre 600-560 Ma, com geração de magmatismo granítico relacionado aos eventos finais do ciclo orogênico Brasiliano-Pan-africano. 


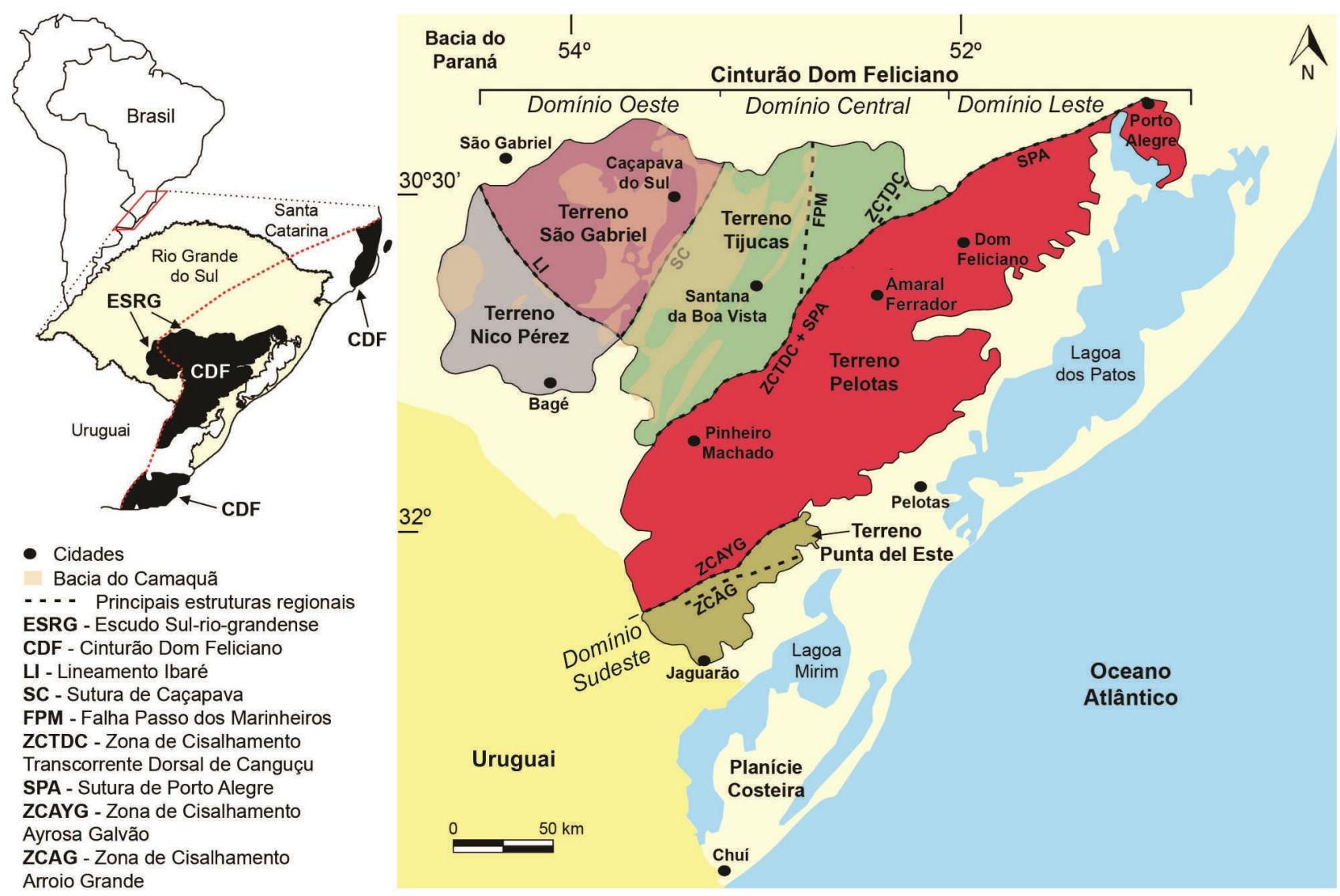

Figura 1. Mapa geológico simplificado ilustrando a disposição dos domínios geofísicos, principais estruturas e compartimentação tectônica do Escudo Sul-rio-grandense (Modificado de Dal Olmo-Barbosa et al., 2021).

Figure 1. Simplified geological map of the Sul-rio-grandense Shield, showing its main geophysical domains, structures, and tectonic compartments (Modified from Dal Olmo-Barbosa et al., 2021).

Ao longo do Cinturão Dom Feliciano ocorrem diversas zonas de cisalhamento que controlam a ascensão e colocação de magmas graníticos sin- a pós-orogênicos. Essas zonas de cisalhamento são agrupadas em parte no Cinturão de Cisalhamento Sul-brasileiro (Bitencourt e Nardi, 2000), uma vasta ocorrência de zonas de cisalhamento anastomosadas com direções predominantes N-S a NE-SW e cinemática sinistral e dextral (Fig. 2A). No Domínio Sudeste do Cinturão Dom Feliciano, próximo à área de estudo, o sistema de zonas de cisalhamento Ayrosa Galvão-Arroio Grande (Vieira et al., 2019a) representa o setor meridional dessa faixa de cisalhamento (Fig. 2B).

As zonas de cisalhamento Ayrosa Galvão e Arroio Grande (Machado et al., 1995) possuem direções preferenciais em torno de $N 50^{\circ}-80^{\circ} \mathrm{E}$, com importantes componentes E-W e cinemática dextral dominante. Este sistema de zonas de cisalhamento se estende para sudoeste no Uruguai, onde é denominado sistema de zonas de cisalhamento Cerro Amaro-Otazo (e.g., Vieira et al., 2019a; Vieira et al., 2021). Este último sistema inflete para sudoeste com a Zona de Cisalhamento Sierra Ballena (Fig. 1A), que representa a extensão uruguaia da Zona de Cisalhamento Dorsal de Canguçu (Vieira et al., 2020) que, por sua vez, representa a principal estrutura tectônica do Domínio Oriental do Cinturão Dom Feliciano no Escudo Sul-rio-grandense (Vieira et al., 2020).

A influência do sistema de zonas de cisalhamento Ayrosa Galvão-Arroio Grande é registrada na formação de amplas zonas miloníticas que afetam em geral as rochas mais antigas da região, ou seja, o embasamento predominantemente metamórfico do Domínio Sudeste do Cinturão Dom Feliciano (Fig. 1B). Este embasamento é representado pelos ortognaisses Arroio Pedrado (idade de cristalização magmática datada em 680 Ma), interpretados como remanescentes do Arco Piratini (Vieira et al., 2019b); as rochas meta-máficas-ultramáficas-sedimentares do 
Complexo Arroio Grande (800-600 Ma - Ramos et al., 2020); e os granitoides mais antigos do Complexo Pinheiro Machado (630-609 Ma Philipp et al., 2002; Loureiro et al., 2015; Bastos et al., 2020). O magmatismo sin-cinemático principal relacionado às referidas zonas de cisalhamento da região de Arroio Grande resulta no alojamento do granito peraluminoso Três Figueiras (Klein et al., 2018; Vieira et al., 2021) e no Granito Chasqueiro (Vieira et al., 2016), foco do presente estudo.

O Granito Chasqueiro compreende um corpo alongado, de orientação N50E (Fig. 2A), com exposições quilométricas (Philipp, 1998; Philipp et al., 2002; Vieira et al., 2016). Esse granito varia de monzo- a sienogranito, possui cor cinza claro e textura porfirítica marcada por megacristais de K-feldspato dispostos em uma matriz hipidiomórfica equigranular grossa (Fig. 2B). É composto por quartzo, K-feldspato, plagioclásio, biotita, hornblenda, minerais opacos (essencialmente ilmenita e magnetita) e acessórios (titanita, zircão, apatita e alanita).

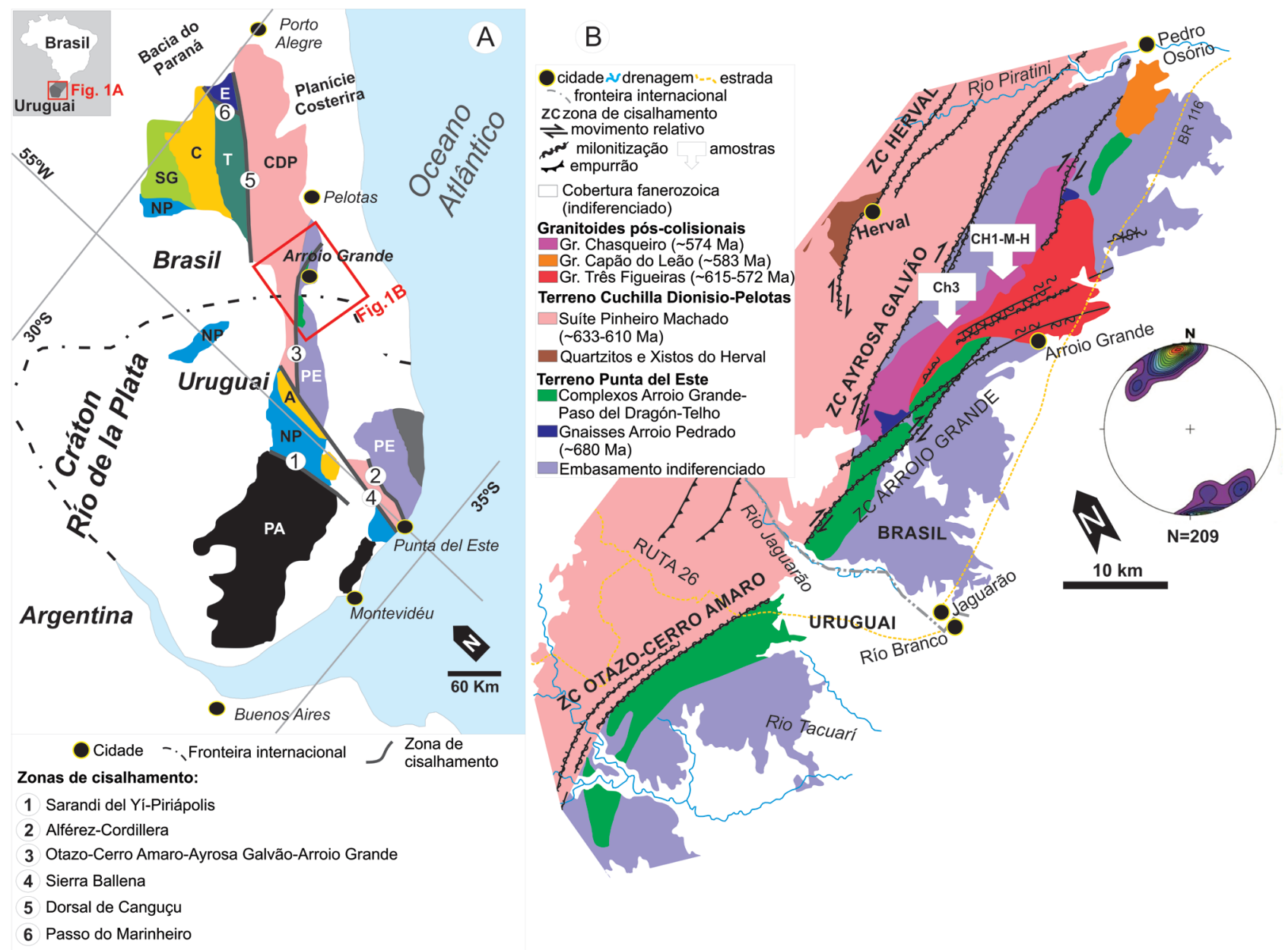

Terreno Piedra Alta (Arqueano/Paleoproterozoico)

Figura 2. Compartimentação tectônica do sul do Brasil e leste da África e localização da área de estudo. A) Localização da região de Arroio Grande, no contexto do Cinturão Dom Feliciano (modificado de Blanco et al., 2011, e Ramos et al., 2020); B) Geologia simplificada da área de estudo, no contexto do extremo sul do Cinturão Dom Feliciano (modificado de Ramos et al., 2018).

Figure 2. Simplified geological maps and location of the study area. A) Location of the Arroio Grande city region, in the context of the Dom Feliciano Belt (modified from Blanco et al., 2011 and Ramos et al., 2020); B) Simplified geology of the study area, in the context of the southernmost Dom Feliciano Belt (modified from Ramos et al., 2018). 
O alinhamento dos megacristais de K-feldspato, em conjunto com os minerais máficos da matriz, marcam uma foliação magmática subvertical que transiciona para uma foliação milonítica proeminente nas bordas do granito, com geração de protomilonitos, sugerindo que o alojamento deste granito esteja relacionado ao sistema de zonas de cisalhamento Ayrosa Galvão-Arroio Grande (Vieira et al., 2016, 2019a).

No Granito Chasqueiro é notável a presença de enclaves dioríticos máficos microgranulares, de diferentes formas e tamanhos (Fig. 2C) que, segundo Vieira et al. (2016), caracterizam um processo de mingling, mantendo suas texturas e composições em função da mistura heterogênea.
Por outro lado, a incorporação mecânica de minerais do granito hospedeiro pelos enclaves máficos, bem como a interação dos enclaves com a hospedeira granítica, caracterizam processos de mistura (mixing), formando rochas híbridas.

Vieira et al. (2016) definem uma idade de cristalização para o Granito Chasqueiro de 574 $\pm 3 \mathrm{Ma}$ (U-Pb em zircão via LA-ICP-MS). Devido às características geoquímicas e isotópicas (Lu$\mathrm{Hf})$, que apresentaram valores de $\varepsilon \mathrm{Hf}$ negativos e próximos a zero, esses autores interpretam a gênese do granito como relacionada a fontes magmáticas crustais com componente de manto subordinado.
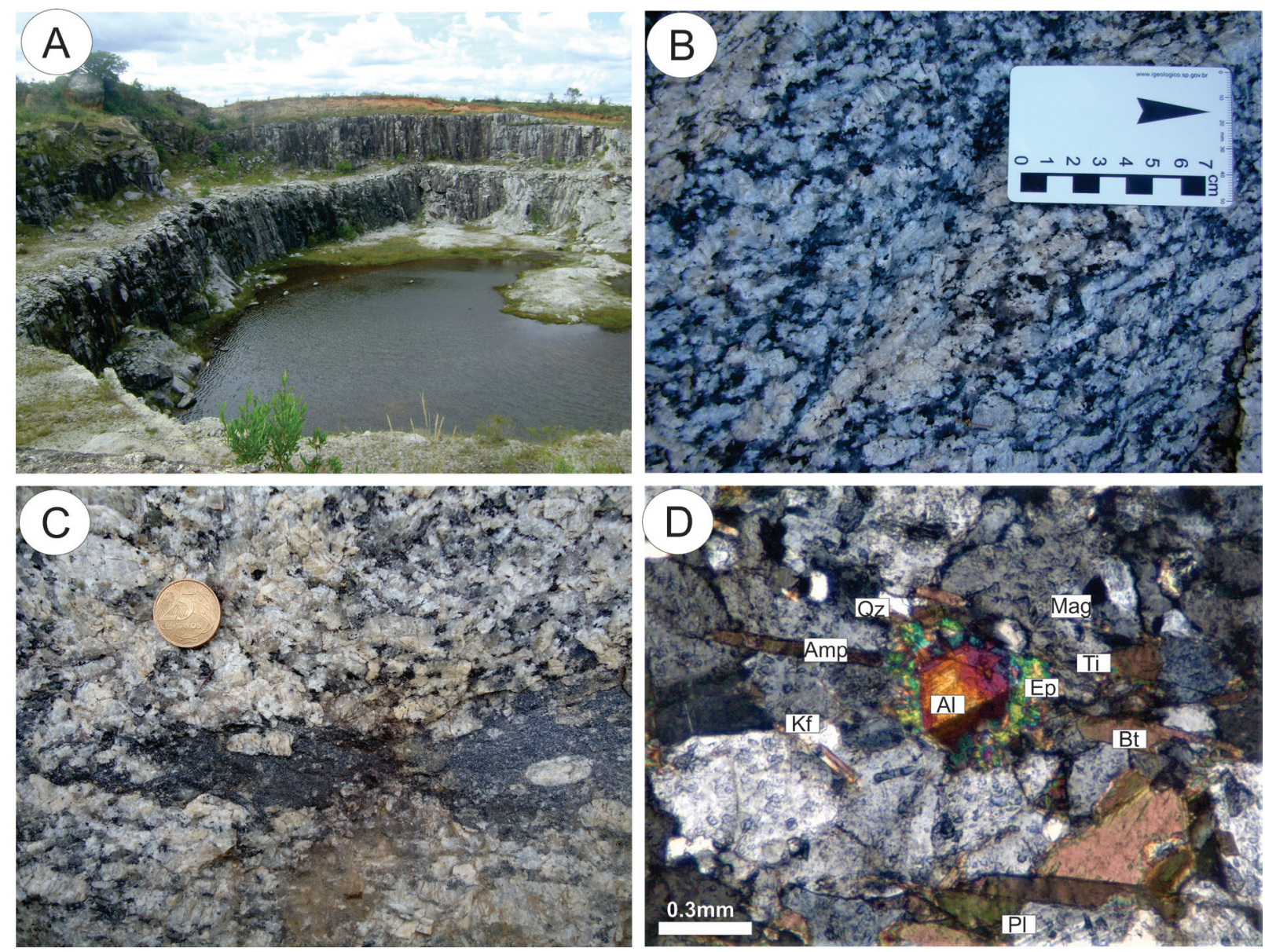

Figura 3. Aspectos de campo do Granito Chasqueiro. A) Pedreira próxima à Arroio Grande, onde se observam amplas exposições do Granito Chasqueiro; B) Textura porfirítica do granito marcada pela presença de fenocristais de K-feldspatos (plano XY); C) Detalhe do enclave máfico microgranular quartzo diorítico que ocorre orientado segundo a foliação magmática do granito e apresenta fenocristais de K-feldspato do granito mecanicamente capturados; D) Associação mineral Kf-PI-Bt-Amp-Al-Ti-Mag observada no Granito Chasqueiro, característica de granitoides do Tipo-I (nicóis cruzados, magnificação de 5x). Abreviações: Bt = biotita; Kf = K-feldspato; Ep = epidoto; Amp = anfibólio; PI = plagioclásio; Mag= Magnetita; $\mathrm{Ti}$ = titanita.

Figure 3. Field aspects of the Chasqueiro Granite. A) Granite quarry near Arroio Grande city, showing the large exposures of the studied granite; B) Detail of the porphyritic texture of the granite, marked by K-feldspar phenocrysts (XY plane); $C$ ) Detail of the quartz-dioritic microgranular mafic enclaves, which are oriented along the magmatic foliation of the granite. The immersed K-feldspar phenocrysts are interpreted as mechanically captured crystals; D) Detail of the Kf-Pl-Bt-Amp-Al-Ti mineral association, typical of l-type granites (crossed polars, $5 x$ magnification). Abbreviations: $B t=$ biotite; $K f=K$-Feldspar; $E p=$ epidote; $A m p=$ amphibole; $P I=$ plagioclase; $A l=$ allanite; $M a g=$ magnetite; $T i=$ titanite . 


\section{Métodos}

Para as análises isotópicas de Sr-Nd (rocha total) foram selecionadas 4 amostras representativas, sendo 2 do Granito Chasqueiro, 1 de enclave máfico diorítico, e 1 de rocha gerada por hibridização. Os termos híbridos conforme descritos por Vieira et al., (2016) apresentam, como o esperado, valores intermediários de $\mathrm{SiO}_{2}$ variando de 62 a 67\% com valores de álcalis variando de 6 a $8 \%$, e a razão $\mathrm{Na}_{2} \mathrm{O} / \mathrm{K}_{2} \mathrm{O}$ em torno de $1 \%$, e teores de $\mathrm{MgO}, \mathrm{FeO}_{(\mathrm{t})}, \mathrm{Fe}_{2} \mathrm{O}_{3}, \mathrm{TiO}_{2}$ e $\mathrm{CaO}$ próximos aos encontrados nas amostras do granito. A localização das amostras é mostrada na figura $2 \mathrm{~B}$ sendo as amostras $\mathrm{CH} 1, \mathrm{CH} 1 \mathrm{M}$ e $\mathrm{CH} 1 \mathrm{H}$ coletadas na pedreira mostrada na figura 3A, enquanto que a amostra $\mathrm{CH} 3$ foi coletada numa região mais a sul.

Para a realização das análises as amostras selecionadas foram cominuídas, preparadas e analisadas no Laboratório de Geologia Isotópica, Centro de Estudos em Petrologia e Geoquímica, Instituto de Geociências, Universidade Federal do Rio Grande do Sul. Para o sistema Sm$\mathrm{Nd}$, as amostras foram lavadas em 2,5 N HCl, sendo posteriormente adicionado traçador com ${ }^{149} \mathrm{Sm} /{ }^{150} \mathrm{Nd}$. Após, as amostras foram completamente dissolvidas em $\mathrm{HF}_{1} \mathrm{HNO}_{3}$ e $\mathrm{HCl}$ concentrados. Resina aniônica LN-B50-A (100$150 \mu \mathrm{m})$ foi usada para a separação de Sm e $\mathrm{Nd}$. Cada elemento foi coletado e as amostras foram secadas e adicionadas, com 0,25 N $\mathrm{H}_{3} \mathrm{PO}_{4}$, a um filamento simples de Ta (para Sm) e a um filamento triplo de Ta-Re-Ta (para $\mathrm{Nd}$ ). As amostras foram lidas em um espectrômetro de massas por ionização térmica multicoletor VG Sector 54, em modo estático. As razões de $\mathrm{Nd}$ foram normalizadas a ${ }^{146} \mathrm{Nd} /{ }^{144} \mathrm{Nd}=0,7219$. O valor padrão de ${ }^{143} \mathrm{Nd} /{ }^{144} \mathrm{Nd}$ usado (padrão $\mathrm{Nd}_{2} \mathrm{O}_{3}$ LaJolla) foi de 0,511859 $\pm 0,000010$. O erro padrão para ${ }^{147} \mathrm{Sm} /{ }^{144} \mathrm{Nd}$ foi de $\pm 1 \%$ ou menor, baseado em análise interativa e recalibração de traçador, e < 0,0057 \% para a razão ${ }^{143} \mathrm{Nd} /{ }^{144} \mathrm{Nd}$. 0 número total de análises foi de 100.

Para o sistema Rb-Sr, as amostras cominuídas foram dissolvidas em $\mathrm{HF}$ e $\mathrm{HNO}_{3}$ concentrados. O Rb e o $\mathrm{Sr}$ foram separados em colunas catiônicas contendo resina catiônica AG50W-X8. As análises foram realizadas no mesmo laboratório, com o mesmo espectrômetro. Os resultados foram calibrados usando o padrão NBS-987 $\left(\mathrm{SrCO}_{3} \mathrm{com}\right.$ razão média de ${ }^{87} \mathrm{Sr} /{ }^{86} \mathrm{Sr}$ de $0,71026 \pm 0,000014)$. Os valores brancos foram menores que 150 pg para Sr. O número total de análises foi de 120.

Os dados geoquímicos de rocha total usados nas discussões foram compilados de Vieira et al. (2016). Todos os dados de geoquímica de rocha total e isotópica ( $\mathrm{Sr}-\mathrm{Nd}$ ) foram tratados com o auxílio do programa GCDKit (Janoušek et al., 2006).

\section{Resultados e discussões}

\subsection{Geoquímica isotópica (Sr-Nd)}

Para este estudo foi utilizada a idade de $574 \mathrm{Ma}$, como referência para o cálculo das razões isotópicas iniciais (Tab. 1). Essa idade foi obtida por Vieira et al. (2016) pelo método U-Pb em zircão via LA-ICP-MS e interpretada como idade de cristalização do granito. As amostras CH-01 e CH-03 correspondem às porções félsicas do Granito Chasqueiro, enquanto as amostras $\mathrm{CH}-1 \mathrm{H}$ e CH-1M correspondem, respectivamente, às porções híbridas e aos enclaves máficos.

\subsection{Afinidades geoquímicas e classificações}

Segundo Vieira et al. (2016), o Granito Chasqueiro apresenta conteúdos de $\mathrm{SiO}_{2}$ entre 70 a 74\%peso pra os termos félsicos, em torno de 60 a $68 \%$ peso para os enclaves máficos, e valores próximos a 70\%peso para os termos híbridos, constituindo um conjunto fortemente diferenciado. Sua associação mineral composta por biotita + anfibólio + titanita + alanita + magnetita (Fig. 3D), em conjunto com características geoquímicas como assinatura metaluminosa a fracamente peraluminosa e afinidade cálcico-alcalina de alto K, sugerem uma composição similar aos granitos do tipo I (Chappell et al., 2012).

A afinidade cálcico-alcalina de alto $K$ segundo Vieira etal. (2016) ébaseada no diagrama proposto por Frost et al. (2001), que relaciona $\mathrm{SiO}_{2}$ com Na $\mathrm{Na}_{2} \mathrm{O}+\mathrm{K}_{2} \mathrm{O}-\mathrm{CaO}$, classificando as rochas segundo sua alcalinidade, onde as amostras do 
granito plotam predominantemente no campo cálcio-alcalino, indicando um magmatismo subalcalino. De acordo com Frost et al. (2001), as classificações dos granitoides em relação aos álcalis indicam diferentes fontes de material de fusão, com os álcali-cálcicos indicando possíveis fontes relacionadas à fusão de magmas básicos com assimilação crustal e os de afinidade química cálcio-alcalina metaluminosa a fracamente peraluminosa correspondendo à fusão de material eminentemente crustal.

Os novos dados obtidos neste trabalho fortalecem a hipótese da composição do Granito Chasqueiro similar aos granitos do tipo I, uma vez que as razões de ${ }^{87} \mathrm{Sr} /{ }^{86} \mathrm{Sr}_{(\mathrm{t})}$ das amostras $\mathrm{CH} 1, \mathrm{CH} 3$ e $\mathrm{CH} 1 \mathrm{H}(0,71049,0,71471$ e 0,71185, respectivamente), bem como os valores de $\mathcal{E} \mathrm{Nd}_{(\mathrm{t})}$ $(-0,36 ;-2,94 ;-1,34)$, são próximos aos sugeridos por Chappell et al. (2012) para os granitoides tipo I $\left({ }^{87} \mathrm{Sr} /{ }^{86} \mathrm{Sr}_{(\mathrm{t})}\right.$ entre 0,704 e 0,712, e valores de $\varepsilon N d_{(t)}$ entre 3,5 a -8,9).

Segundo Pitcher (1983), os granitos tipo I podem ser subdivididos em Cordilheiranos e Caledonianos. Os granitos tipo I Cordilheiranos possuem composição cálcico-alcalina trondhjemítica a tonalítica, sendo, em geral, pobres em $\mathrm{K}_{2} \mathrm{O}$. Sua gênese é relacionada aos processos orogênicos de margem continental ativa, caracterizados por plutonismo de longa duração e geração de arcos magmáticos continentais do tipo andino.
Os granitos tipo I Caledonianos assim como os Cordilheiranos são cálcico-alcalinos, entretanto apresentam um aumento do teor de $\mathrm{K}_{2} \mathrm{O}$ refletindo em séries cálcico-alcalinas granodioríticas a monzoníticas. Segundo Pitcher (1983), estes granitos são relacionados aos estágios orogênicos finais no interior da crosta, após o término da subducção. Com o fim da compressão e dos movimentos laterais ocorre o relaxamento do cinturão orogênico, gerando uma tectônica extensional e transcorrente com movimentações direcionais e verticais de blocos. Para este autor estes deslocamentos propiciam a fusão da base da crosta e o topo do manto litosférico, promovendo a produção de magmas graníticos do tipo I Caledonianos associados a magmas máficos de composição toleítica a cálcico-alcalina.

A partir de suas características mineralógicas, presença de enclaves máficos, e afinidade cálcico-alcalina alto-K, O Granito Chasqueiro pode ser classificado como do tipo I Caledoniano. Essa classificação é compatível com as hipóteses anteriormente formuladas para a evolução deste granito (Vieira et al., 2016), as quais sugerem um ambiente pós-colisional, com magmas modificados por contaminação com fusões da crosta inferior, resultantes do relaxamento termal dessa porção da crosta, e alojamento do plúton controlado por zonas de cisalhamento transcorrentes dúcteis.

Tabela 1. Resultados de geoquímica isotópica (sistemas $\mathrm{Rb}-\mathrm{Sr}$ e $\mathrm{Sm}-\mathrm{Nd}$ em rocha total) para as amostras do Granito Chasqueiro. *Dados extraídos de Vieira et al. (2016).

Table 1. Isotope geochemistry results (whole rock Rb-Sr and Sm-Nd systems) for the samples of the Chasqueiro Granite. * Data from Vieira et al. (2016)

\begin{tabular}{|c|c|c|c|c|c|c|c|c|c|c|c|c|}
\hline Amostra & Idade (Ma) & $\mathrm{Sr}(\mathrm{ppm})^{*}$ & $\mathrm{Rb}$ (ppm)* & ${ }^{87} \mathrm{Sr} /{ }^{86} \mathrm{Sr}$ (i) & ${ }^{87} \mathrm{Sr} /{ }^{86} \mathrm{Sr}(\mathrm{t})$ & Sm (ppm)* & $\mathrm{Nd}(\mathrm{ppm})^{*}$ & $\begin{array}{l}{ }^{143} \mathrm{Nd} /{ }^{144} \mathrm{Nd} \\
\text { (i) }\end{array}$ & $\begin{array}{c}{ }^{143} \mathrm{Nd} /{ }^{144} \mathrm{Nd} \\
\text { (t) }\end{array}$ & $\varepsilon N d$ & $\varepsilon N d(t)$ & $\mathrm{TDM}(\mathrm{Ga})$ \\
\hline $\mathrm{CH}-01$ & 574 & 142,6 & 199,5 & 0,742836 & 0,71049 & 8,68 & 60,22 & 0,512208 & 0,511881 & $-8,39$ & $-0,36$ & 1,06 \\
\hline $\mathrm{CH}-03$ & 574 & 151,9 & 174 & 0,741195 & 0,71471 & 7,83 & 51,18 & 0,512096 & 0,511748 & $-10,58$ & $-2,94$ & 1,18 \\
\hline $\mathrm{CH}-1 \mathrm{H}$ & 574 & 184,1 & 190,9 & 0,735826 & 0,71185 & 7,91 & 45,89 & 0,512222 & 0,511831 & $-8,12$ & $-1,34$ & 1,14 \\
\hline $\mathrm{CH}-1 \mathrm{M}$ & 574 & 508,9 & 98,5 & 0,751197 & 0,74672 & 7,62 & 45,59 & 0,512195 & 0,511815 & $-8,65$ & $-1,63$ & 1,15 \\
\hline
\end{tabular}



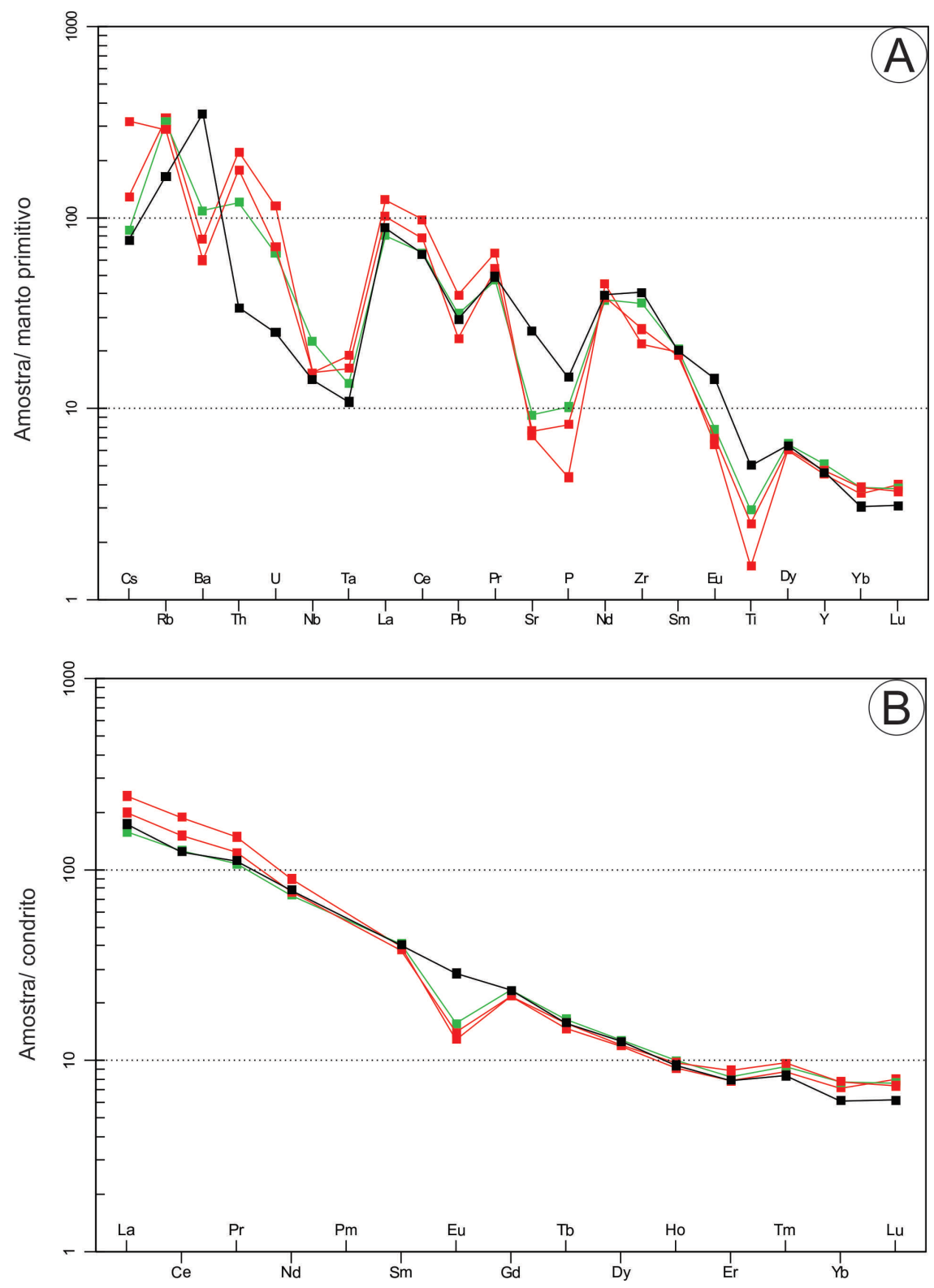

Figura 4. Diagramas multielementares das amostras do Granito Chasqueiro. A) Diagrama multielementar normalizado para o manto primitivo de McDonough \& Sun (1995); B) Diagrama de ETR, normalizado para o condrito de Nakamura (1994). Amostras em vermelho $=$ Granito Chasqueiro; verde $=$ Termo Hibrido; preto $=$ enclave máfico.

Figure 4. Behavior of the Chasqueiro Granite samples in multi-element spider diagrams. A) Primitive mantle-normalized (McDonough and Sun, 1995) multi-element spider diagrams; B) Chondrite-normalized REE diagram (Nakamura, 1974). Red samples $=$ Chasqueiro Granite; Green Sample $=$ hybrid; Black sample = mafic enclave . 

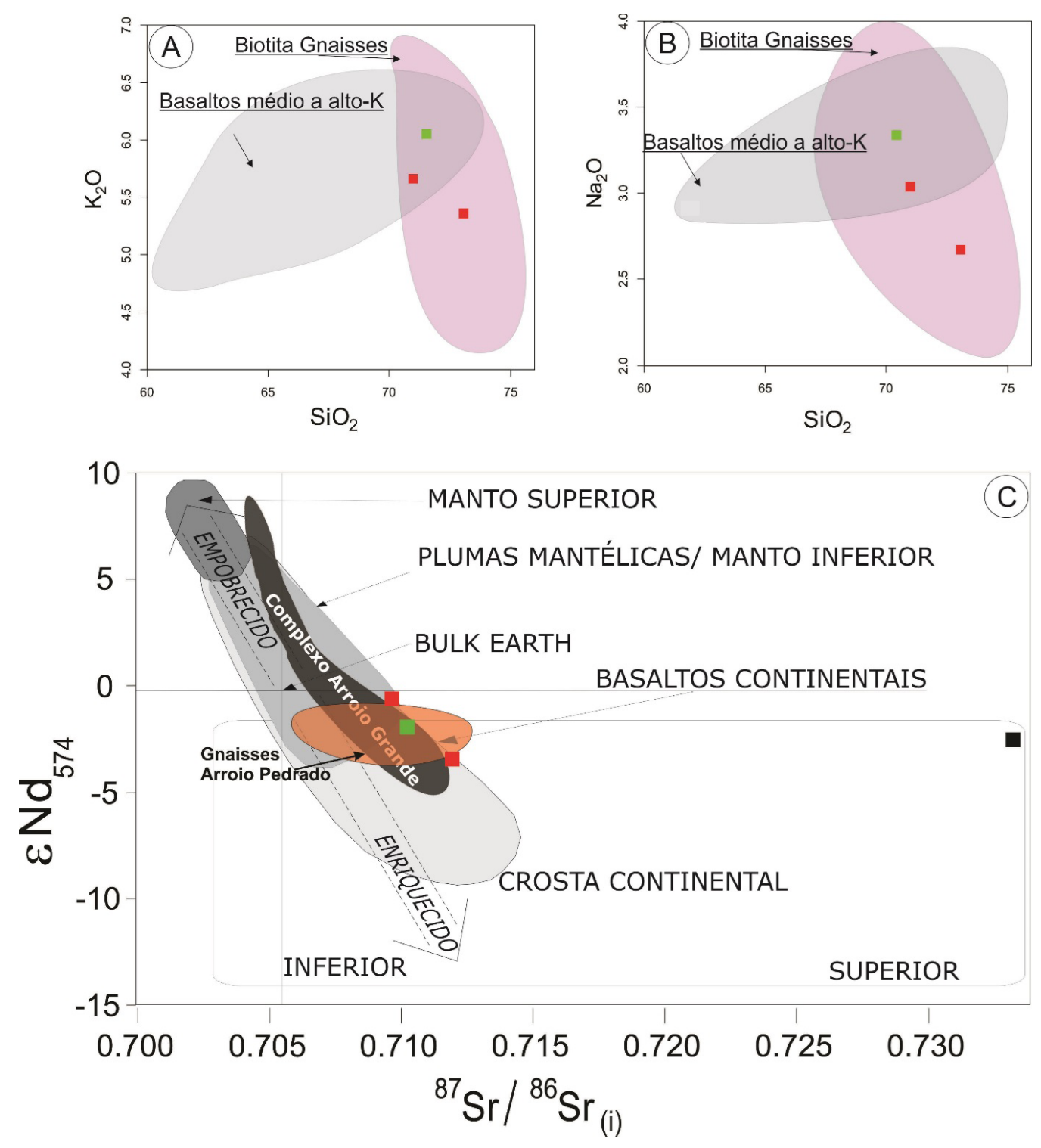

Figura 5. Diagramas de geoquímica de rocha total e isotópica. A) $\mathrm{K}_{2} \mathrm{O}$ vs. $\left.\mathrm{SiO}_{2} ; \mathrm{B}\right) \mathrm{Na}_{2} \mathrm{O}$ vs. $\mathrm{SiO}_{2}$. Os campos de fusões experimentais destacados nas figuras $A$ e $B$ se referem a granitos gerados a partir da fusão de biotita gnaisses (3-15 kb e 850-930 ${ }^{\circ} \mathrm{C}$ - Patiño Douce \& Beard, 1995), e rochas basálticas de médio a alto $\mathrm{K}\left(700 \mathrm{Mpa}\right.$ e $825-975^{\circ} \mathrm{C}-\mathrm{Sisson}$ et al., 2005); C) Diagrama $\varepsilon N d$ versus ${ }^{87} \mathrm{Sr}^{86} \mathrm{Sr}_{(i)}$, modificado de DePaolo (1981). Dados isotópicos do Complexo Arroio Grande retirados de Ramos et al. (2018 e 2020). Dados isotópicos dos Gnaisses Arroio Pedrado retirado de Vieira et al. (2019b). Símbolos conforme a figura 4.

Figure 5. Whole rock and isotope geochemistry diagrams. A) $\mathrm{K} 2 \mathrm{O}$ vs. $\mathrm{SiO}_{2}$; B) $\mathrm{Na}_{2} \mathrm{O}$ vs. $\mathrm{SiO}_{2}$. The fields in the diagrams for experimental melts refer to granites generated by partial melting of biotite gneisses $\left(3-15 \mathrm{~kb}\right.$ and $850-930{ }^{\circ} \mathrm{C}-P a t i n ̃ o$ Douce \& Beard, 1995) and medium- to high-K basaltic rocks (700 MPa and 825-975 ${ }^{\circ} \mathrm{C}-$ Sisson et al., 2005); C) $\varepsilon N d$ versus ${ }^{87} \mathrm{Sr} /{ }^{86} \mathrm{Sr}_{\text {(iip }}$ diagram modified from DePaolo (1981). Isotopic data from Arroio Grande Complex extracted from Ramos et al. (2018 and 2020). Isotopic data from Arroio Pedrado Gneiss extracted from Vieira et al. (2019b). Symbols as in figure 4. 


\subsection{Possíveis fontes e processos magmáticos}

Segundo Anderson (1996), a fugacidade do oxigênio $\left(\mathrm{fO}_{2}\right)$, em magmas silicáticos, exerce muito mais controle sobre as composições minerais do que outros parâmetros intensivos, como P e T. No caso do Granito Chasqueiro, a assembleia mineral constituída por titanita + magnetita + quartzo \pm anfibólio (com formação de coroa de epidoto, Fig. 3D) implica, segundo Wones (1989), em uma fugacidade de oxigênio relativamente alta durante a formação deste granito.

De acordo com diversos autores como Patiño Douce e Beard (1995), Moyen (2009) e Nandedkar et al. (2014), os granitos do tipo I podem se formar em decorrência da fusão de rochas metaluminosas. Segundo esses autores, características encontradas nas amostras do Granito Chasqueiro e seu termo híbrido, como os padrões ETR pesados relativamente planos (Fig. 4A), baixas razões $\mathrm{Gd} / \mathrm{Yb}(0,8-4,7)$ e baixas razões $\mathrm{Sr} / Y$ (2-54), anomalias negativas fracas a moderadas de Eu (Eu/Eu * = 0,10 a 0,93, Fig.3B) demonstram possível fusão crustal com plagioclásio e hornblenda no resíduo. Esse padrão difere do encontrado na amostra do enclave máfico que, além da ausência de anomalias negativas de Eu, apresenta um padrão de enriquecimento em elementos incompatíveis distinto das amostras do granito.

Granitos evoluídos essencialmente por cristalização fracionada enriquecem em elementos incompatíveis como, por exemplo, La, Zr e ETRs (Gill, 2010). No caso do Granito Chasqueiro, os maiores valores de enriquecimento em elementos incompatíveis foram encontrados nos enclaves máficos, enquanto os termos híbridos apresentam teores médios entre o granito e os enclaves. Isso sugere uma fonte diferente para os enclaves em relação aos granitos, bem como um processo de mistura de magmas como processo fundamental para sua evolução.

Nos gráficos de $\mathrm{K}_{2} \mathrm{O}$ e $\mathrm{Na}_{2} \mathrm{O}$ versus sílica (Fig. 5A e 5B) com campos para geração de granitoides a partir de fusões experimentais compilados da literatura por Chen et al. (2013), as amostras do Granito Chasqueiro e do termo híbrido apresentam composições semelhantes às produzidas pela fusão parcial de biotitagnaisses.

As razões de ${ }^{87} \mathrm{Sr} /{ }^{86} \mathrm{Sr}_{(\mathrm{t})}(0,71049$ a 0,71471) e os valores negativos de $\mathcal{E} \mathrm{Nd}_{(t)}$ sugerem fontes relacionadas à crosta continental inferior (Fig. 5C), com TDM em torno de 1,1 Ga. Porém, os valores fracamente negativos de $\varepsilon \mathrm{Nd}_{(t)}(-0,36$ a $-2,94)$, bem como os valores de $\mathcal{E H f}_{(t)}(-0,24$ a $-5,21)$ em zircões obtidos por Vieira et al. (2016), sugerem participação mantélica na gênese dessas rochas. Este fato é corroborado pelos valores de mg\# (10-35 - Vieira et al., 2016), que são maiores que os encontrados em fusões crustais, determinadas experimentalmente por Rapp e Watson (1995), sendo esses valores, possivelmente associados a um retrabalhamento crustal com a presença de um componente mantélico.

No que tange aos enclaves máficos, a razão ${ }^{87} \mathrm{Sr} /{ }^{86} \mathrm{Sr}_{(\mathrm{t})}$ de 0,74672 é mais alta do que as encontradas nas amostras dos granitos, e o valor negativo de $\varepsilon \mathrm{Nd}_{(\mathrm{t})}(-1,63)$ corroboram com a hipótese de uma possível fonte diferente para os enclaves máficos (Fig. 5A e 5B), bem como um processo evolutivo diferente (Fig. 5C). Os valores de $\varepsilon \mathrm{Nd}_{(\mathrm{t})}$ dos enclaves máficos são comuns no manto enriquecido (como os OIB por exemplo) e a alta razão ${ }^{87} \mathrm{Sr} /{ }^{86} \mathrm{Sr}_{(t)}$ possivelmente se deve às trocas que acontecem durante a evolução e mistura desse complexo magmatismo. Os termos híbridos refletem valores de ${ }^{87} \mathrm{Sr} /{ }^{86} \mathrm{Sr}_{(t)}$ e $\varepsilon \mathrm{Nd}_{(t)}$ intermediários entre os termos máficos e félsicos, reforçando a intepretação destas rochas como geradas por mistura homogênea de magmas e/ou hibridização.

De acordo com Vieira et al. (2016), o Granito Chasqueiro apresenta zircões herdados com idades variando de 680 a 899 Ma semelhantes às idades das rochas do embasamento da região de Arroio Grande (Vieira et al., 2019b; Cruz, 2019; Ramos et al., 2020). As rochas do embasamento, de acordo com esses autores, mostram composições isotópicas que reforçam a hipótese destas rochas como possíveis fontes crustais relacionadas à gênese deste granito (Fig. 5C).

Diferentemente dos enclaves máficos, a cristalização fracionada parece ter desempenhado um papel mais importante durante a evolução magmática do granito, não 
sendo, entretanto, caracterizada como o principal processo de sua evolução. As correlações negativas entre $\mathrm{SiO}_{2}$ e $\mathrm{MgO}, \mathrm{CaO}, \mathrm{TiO}_{2}, \mathrm{Al}_{2} \mathrm{O}_{3}, \mathrm{Sr}$, Zr (Vieira et al., 2016) e a pequena variação de ${ }^{87} \mathrm{Sr} /{ }^{86} \mathrm{Sr}$ versus $\mathrm{SiO}_{2}$ (Fig. 5A) corroboram com essa hipótese (Gill, 2010). A depleção dos elementos Eu - Ba e Eu - Sr (Fig. 4A e 4B) podem indicar, respectivamente, o fracionamento de feldspato alcalino e plagioclásio. O fracionamento da biotita também poderia ter contribuído para as anomalias negativas de Ba e Nb. Além disso, as anomalias negativas de $\mathrm{Nb}$-Ti provavelmente também estão relacionadas ao fracionamento de fases contendo Ti (por exemplo, ilmenita, titanita). Entretanto, as anomalias negativas de $\mathrm{Ba}$ e $\mathrm{Nb}$ e positiva de $\mathrm{Rb}$ são semelhantes ao padrão observado para o embasamento gnáissico da região (Vieira et al., 2019b), podendo ser resultado tanto da interação entre o magmatismo que originou o granito e o embasamento da região, como da fusão parcial desses gnaisses (interação melt-rocha). São observadas feições similares às de fusão in situ nos Gnaisses Arroio Pedrado (Figs. 6A e 6B), entretanto essas feições ainda são pouco estudadas.

Para avaliar a atuação e importância do fracionamento mineral no Granito Chasqueiro, foi utilizado o modelo de fracionamento de Rayleigh usando diagramas do tipo log - log de Ba versus Sr (Fig. 7A) e Ba/ Sr versus Sr (Fig. 7B). Em ambos os diagramas, o melhor modelo para a diferenciação magmática do Granito Chasqueiro é descrito pelo fracionamento de plagioclásio (35\%), K-feldspato (50\%), biotita (10\%) e anfibólio (5\%). Entretanto, as quantidades adequadas de fracionamento de cada mineral não devem ser consideradas confiáveis, uma vez que essas estatísticas são baseadas em um processo de diferenciação magmática em um sistema fechado, o qual não parece ser o caso do granito estudado, onde a reciclagem de unidades crustais mais antigas pode ter contribuído na evolução magmática, como discutido anteriormente.

\section{O Granito Chasqueiro como discutido anteriormente contém enclaves dioríticos} máficos microgranulares que exibem relações de campo - e.g., textura de granulação fina, formas arredondadas e a ocorrência de fenocristais de K-feldspato que cortam a fronteira enclave/granito, que sugerem coexistência de diferentes tipos de magmas. Essas características indicam que esses enclaves são glóbulos de magma máfico que foram injetados e misturados e/ou mesclados com o magma hospedeiro (e.g., Zhang et al., 2016).
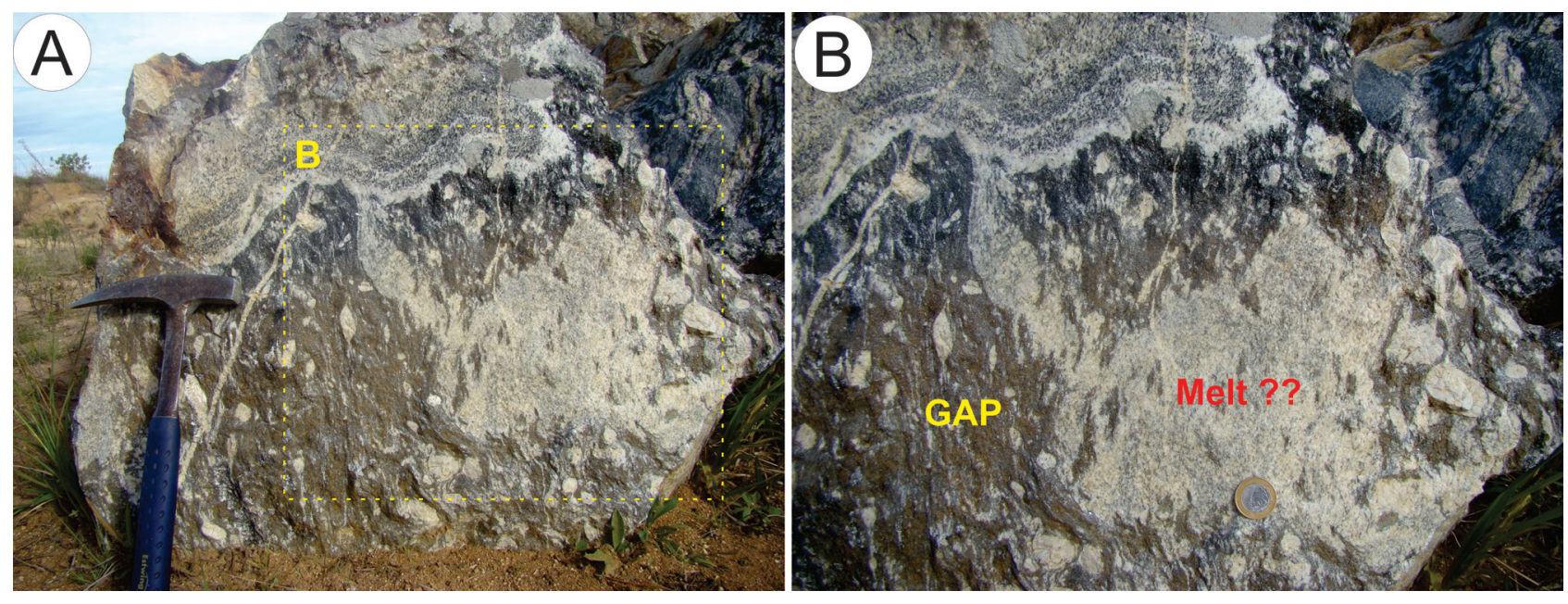

Figura 6. Feições petrográficas observadas nos Gnaisses Arroio Pedrado. (A) Feições similares às de fusões in situ, tais como a migração de melt e formação de um possível bolsão; (B) Mostrando as feições que sugerem fusões in situ em detalhe. Abreviação: GAP = Gnaisse Arroio Pedrado.

Figure 6. Petrographic features observed in the Arroio Pedrado Gneisses. A) Outcrop of the Arroio Pedrado Gneiss. It is possible to observe features which suggest partial melting, such as melt migration and generation of a melt pocket; $B$ ) The features which suggest partial melting in detail. Abbreviation: GAP = Arroio Pedrado Gneiss. 

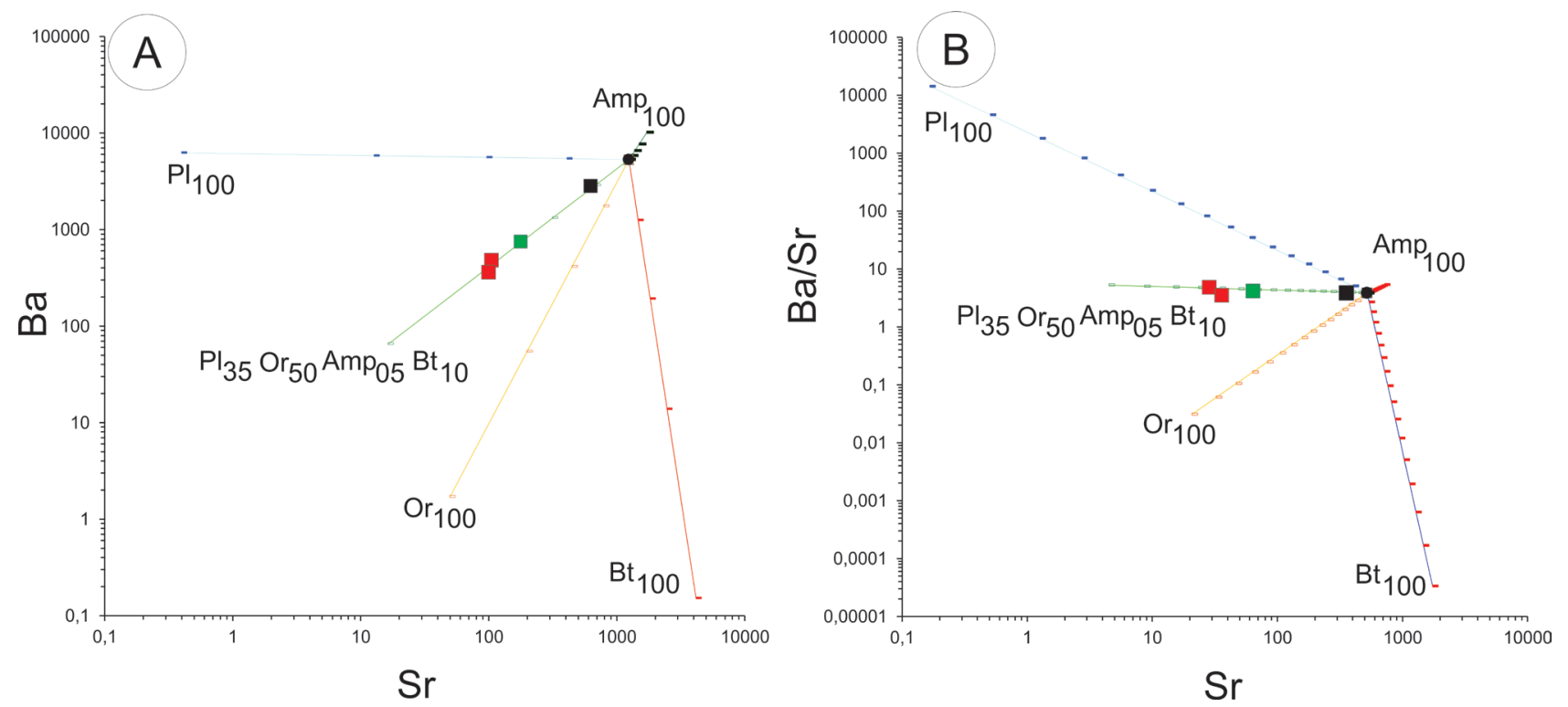

Figura 7. Modelos de fracionamento de Rayleigh. A) Ba vs. Sr; B) Ba/ Sr vs. Sr. Símbolos conforme a figura 4. Abreviações; $\mathrm{PI}$ = plagioclásio, $\mathrm{Or}=\mathrm{K}$-felsdspato; $\mathrm{Bt}=$ biotita; $\mathrm{Amp}=$ anfibólio.

Figure 7. Rayleigh fractionation models. A) Ba versus Sr; B) Ba/Sr versus Sr. Symbols as in figure 4. Abbreviations: $\mathrm{Pl}=$ plagioclase; Or = K-Feldspar Bt = biotite; $A m p=$ amphibole.

Portanto, a mistura de magmas, assim como a cristalização fracionada, são processos importantes na evolução deste granito, onde a presença do magmatismo máfico pode indicar o envolvimento do magma gerado na crosta superior onde ele se aloja, gerando assim a fusão parcial da crosta, dando origem ao granito. Dessa maneira, o magmatismo máfico pode ter assimilado a crosta-fonte durante o processo de alojamento, imprimindo algumas características nesse magma, o que explicaria o valor elevado da razão ${ }^{87} \mathrm{Sr} /{ }^{86} \mathrm{Sr}_{(\mathrm{t})}$ encontrada na amostra $\mathrm{CH} 1-\mathrm{M}$.

\section{Conclusões}

O Granito Chasqueiro pode ser classificado como um granito do Tipo-I altamente diferenciado, com elevados teores de $\mathrm{SiO}_{2}$, cristalizado em condições de alta fugacidade de oxigênio em um ambiente pós-colisional. Seu alojamento está provavelmente relacionado ao sistema de zonas de cisalhamento transcorrentes dúcteis Ayrosa Galvão-Arroio Grande.

O granito possui relações de mistura homogênea e heterogênea com magmas máficos, possivelmente contemporâneos. A verificação de mistura de magmas sugere que a participação do componente máfico foi importante e contínua durante todo o processo evolutivo do granito. Todavia, algumas características, como enriquecimento em ETR leves em relação aos pesados, aumento da peraluminosidade, valores de ${ }^{87} \mathrm{Sr} /{ }^{86} \mathrm{Sr}_{(\mathrm{t})}(0,71049$ a 0,71471 ) e valores negativos de $\varepsilon \mathrm{Nd}_{(t)}$ próximos a zero, em conjunto com TDM em torno de 1,3 Ga, sugerem granitogênese a partir de uma fonte dominantemente crustal, com participação mantélica subordinada. As fontes crustais, por sua vez, seriam oriundas do retrabalhamento do embasamento regional, no caso o Gnaisse Arroio Pedrado.

Além da mistura de magmas e retrabalhamento do embasamento metamórfico, a cristalização fracionada é um dos principais processos de evolução deste granito. Esse fato pode ser observado nas concentrações e depleções marcantes em Ba, Sr, P, Nb, Ti, e Eu, que reforçam a extensa cristalização fracionada dos líquidos primários.

Portanto, o Granito Chasqueiro representa a evolução de um complexo sistema magmático, que se diferenciou da fonte por meio de processos de mistura de magmas, retrabalhamento crustal e cristalização fracionada, resultando em um granito altamente diferenciado, com composições semelhantes às dos granitos do 


\section{Tipo-I Caledonianos.}

Apesar do pequeno universo amostral, é possível com base nos dados isotópicos inéditos apresentados neste estudo, em conjunto com a reavaliação de dados geoquímicos previamente publicados, propor um simplificado modelo petrogenético para o Granito Chasqueiro, em um ambiente pós-colisional. Inicialmente, ocorreu a extração de magmas parentais provavelmente derivados do manto, favorecidos pelo alívio da pressão causada pela atividade das zonas de cisalhamento regionais. Em sequência, esses líquidos se fracionaram e ascenderam a níveis crustais superiores, retrabalhando possivelmente o embasamento da região e diferenciando-se em rochas com padrões químicos distintos, por meio de processos de mistura de magmas e cristalização fracionada, até a sua colocação final em torno de $574 \mathrm{Ma}$. Cabe salientar que este modelo demanda um universo amostral maior e estatisticamente mais representativo para ser efetivamente validado.

Agradecimentos. Ao CNPq pelo auxílio e bolsa concedida a DTV (Processo n 140461/2016-7).

\section{Referências}

Almeida, F.F.M., Hasui, Y., Brito-Neves, B.B. \& Fuck, R.A. 1981. Brazilian structural provinces: an introduction. Earth Science Review, 17: 1-29.

Anderson, J.L. 1996. Status of thermobarometry in granitic batholiths. Transactions of the Royal Society of Edinburgh: Earth Sciences, 87(1-2): 125-138.

Babinski M., Chemale Jr., F., Van Schmus W.R., Hartmann L.A. \& Silva L.C. 1997. U-Pb and Sm-Nd geochronology of the Neoproterozoic Granitic-Gneissic Dom Feliciano Belt, Southern Brazil. Journal of South American Earth Sciences, 10(3-4): 263-274.

Bastos, V.A., Koester, E., Lenz, C., Dal OlmoBarbosa, L., Porcher, C.C., Loureiro, O.L, Vieira, D.T., Ramos, R.C. \& Cedeño, D.G. 2020. Contribution to the understanding of the Pinheiro Machado Complex (Dom Feliciano Belt, Brazil): A study of textures, mineral chemistry, and crystallization conditions. Geological Journal, 56(2): 1012- 1033.
Bitencourt, M.F. \& Nardi, L.V.S. 2000. Tectonic setting and sources of magmatism related to the Southern Brazilian Shear Belt. Revista Brasileira de Geociências, 30: 184-187.

Blanco, G., Germs, G.J.B., Rajesh, H.M., Chemale Jr., F., Dussin, I.A., Justino, D., 2011. Provenance and paleogeography of the Nama Group (Ediacaran to early Palaeozoic, Namibia): petrography, geochemistry and $\mathrm{U}-\mathrm{Pb}$ detrital zircon geochronology. Precambrian Research, 187: 15-32.

Bossi, J. \& Gaucher, C. 2004. The Cuchilla Dionisio Terrane, Uruguay: an allochthonous block accreted in the Cambrian to SW-Gondwana. Gondwana Research, 7(3): 661-674.

Brito-Neves, B.B., Fuck, R.A. \& Pimentel, M.M. 2014. The Brasiliano collage in South America: a review. Brazilian Journal of Geology, 44(3): 493-518.

Brown, M. 2013. Granite: From genesis to emplacement. Bulletin of the Geological Society of America, 125: 1079-1113.

Chappell, B.W., Bryant, C.J. \& Wyborn, D. 2012. Peraluminous I-type granites. Lithos, 153: 142-153.

Chemale, F., Hartmann, L.A. \& Silva, L.C. 1995. Stratigraphy and tectonism of the Brasiliano Cycle in southern Brazil. Communications of the Geological Survey of Namibia, 10: 153-168.

Chen, J.Y., Yang J.H., Zhang, J.H., Sun, J.F. \& Wilde, S.A. 2013. Petrogenesis of the Cretaceous Zhangzhou batholith in southeastern China: zircon $\mathrm{U}-\mathrm{Pb}$ age and $\mathrm{Sr}-\mathrm{Nd}-\mathrm{Hf}-\mathrm{O}$ isotopic evidence. Lithos, 162-163: 140-156.

Condie, K.C. \& Aster, R.C. 2010. Episodic zircon age spectra of orogenic granitoids: the supercontinent connection and continental growth. Precambrian Research, 180(3-4): 227-236.

Condie, K.C., Belousova, E., Griffin, W.L. \& Sircombe, K.N. 2009. Granitoid events in space and time: constraints from igneous and detrital zircon age spectra. Gondwana Research, 15(3-4): 228-242.

Costa, A.F.U. 1997. Teste e modelagem geofísica da estruturação das associações litotectônicas pré-cambrianas no Escudo Sul-rio-grandense. Porto Alegre. 291p. Tese de Doutorado. Programa de Pós-graduação em Geociências, 
Instituto de Geociências, Universidade Federal do Rio Grande do Sul.

Cruz, R.F. 2019. Projeto Sudeste do Rio Grande do Sul: escalas 1:250.000 e 1:100.000; estado do Rio Grande do Sul/ Relatório do Programa geologia, mineração e transformação mineral. CPRM, Porto Alegre.

Dal Olmo-Barbosa, L., Koester, E., Vieira, D. T., Porcher, C. C. \& Grings, D. C. 2021. Crystallization ages of the basic intrusive Ediacaran magmatism in the southeastern Dom Felicia- no Belt, southernmost Brazil: implications in the belt geodynamic evolution. Journal of South American Earth Sciences, 108: 103143.

DePaolo, D.J. 1981. Neodymium isotopes in the Colorado Front Range and crust-mantle evolution in the Proterozoic. Nature, 291:193196.

Fernandes, L.A.D., Menegat, R., Costa, A.F.U., Koester, E., Porcher, C.C., Tommasi, A., Kraemer, G., Ramgrab, G.R. \& Camozzato, E. 1995. Evolução tectônica do Cinturão Dom Feliciano no Escudo Sul-riograndense: Parte I - Uma contribuição a partir do registro geológico. Revista Brasileira de Geociências, 25(4): 351-374.

Fernandes, L.A.D., Menegat, R., Costa, A.F.U., Koester, E., Porcher, C.C., Tommasi, A., Kraemer, G., Ramgrab, G.R. \& Camozzato, E. 1995b. Evolução tectônica do Cinturão Dom Feliciano no Escudo Sul-riograndense: Parte II - Uma contribuição a partir das assinaturas geofísicas. Revista Brasileira de Geociências, 25(4): 375-384.

Fragoso-César, A.R.S., Figueiredo, M.C.H., Soliani, E. \& Faccini, U.F. 1986. O Batólito Pelotas (Proterozóico Superior/ Eo- Paleozóico) no Escudo do Rio Grande do Sul. In: Congresso Brasileiro de Geologia 34., 1986, Goiânia, Anais..., 3, p. 1322-1343.

Frost B.R., Barnes C.G., Collins W.J., Arculus R.J., Ellis D.J. \& Frost C.D.A. 2001. Geochemical classification for granitic rocks. Journal of Petrology, 42(11):2033-2048.

Gaucher, C., Sial, A., Halverson, G. \& Frimmel, H. 2009. Neoproterozoic-Cambrian tectonics, global change and evolution: a focus on South Western Gondwana. Developments in
Precambrian Geology, v. 16, 498p.

Gill, R. 2010. Granitic rocks. In: Gill, R. (Ed.) Igneous rocks and processes: a practical guide. Oxford, Wiley-Blackwell, p. 241-290.

Gray, D.R., Foster, D.A., Meert, J.G., Goscombe, B.D., Armstrong, R., Trouw, R.A.J., Passchier, C.W. 2008. A Damara orogen perspective on the assembly of southwestern Gondwana. In: Pankhurst, R.J., Trouw, R.A.J., Brito-Neves, B.B., De Wit, M.J. (Eds.), West Gondwana: Precenozoic Correlations across the South Atlantic Region. Geological Society of London, Special Publication, pp. 257-278.

Hartmann, L.A., Chemale Jr., F. \& Philipp, R.P. 2007. Evolução geotectônica do Rio Grande do Sul no Pré-Cambriano. In: Ianuzzi, R.; Frantz, J.C. (Eds.). 50 Anos de Geologia: Instituto de Geociências. Contribuições. Porto Alegre, Comunicação e Identidade, p. 97-123.

Hueck, M., Oyhantçabal, P., Philipp, R.P., Basei, M.A.S., Siegesmund, S., 2018. The Dom Feliciano Belt in southern Brazil and Uruguay. In: Siegesmund, S., Basei, M., Oyhantçabal, P., Oriolo, S. (Eds.), Geology of Southwest Gondwana. Springer, Regional Geology Reviews, pp. 267-302.

Janoušek, V., Farrow, C.M. \& Erban, V. 2006. Interpretation of whole-rock geochemical data in igneous geochemistry: introducing Geochemical Data Toolkit (GCDkit). Journal of Petrology, 47(6): 1255-1259.

Klein, F.G., Koester, E., Vieira, D.T., Porcher, C.C., Ramos, R.C. \& Philipp, R.P. 2018. Geologia do Granito Três Figueiras: magmatismo peraluminoso de $585 \mathrm{Ma}$ no sudeste do Cinturão Dom Feliciano. Pesquisas em Geociências, 45(2): e665.

Loureiro, P.O., Koester, E., Weinberg, R.F., Porcher, C.C., Pimentel, M.M. \& Knijnik, D. 2015. Magmatic evolution of Pinheiro Machado Complex in Monte Bonito region, Southern Brazil. In: HUTTON SYMPOSIUM ON GRANITES ANd ReLATEd Rocks, VIII., 2015, Florianópolis, Resumos..., p. 125.

Machado, R., Philipp, R.P. \& Mello, F. 1995. Reconhecimento de zonas de cisalhamento dúcteis de alto ângulo com cinemática superposta na extremidade sul do Batólito Pelotas, RS. In: SIMPósıo NACIONAL DE EsTUdos 
Tectônicos, 5, 1995, Gramado, Boletim de Resumos Expandidos, p. 52-53.

McDonough, W.F. \& Sun, S.S. 1995. The composition of the Earth. Chemical Geology, 120: 223-253.

Moyen, J.F. 2009. High Sr/Y and La/Yb ratios: the meaning of the "adakitic signature". Lithos, 112:556-574.

Nakamura, N. 1974. Determination of REE, Ba, Fe, $\mathrm{Mg}, \mathrm{Na}$, and $\mathrm{K}$ in Carbonaceous and Ordinary Chondrites. Geochimica et Cosmochimica Acta, 38: 757-775

Nandedkar, R.H., Ulmer, P. \& Müntener, O. 2014. Fractional crystallization of primitive, hydrous arc magmas: an experimental study at 0.7 GPa. Contribution Mineral Petrology, 167: 1015.

Patiño Douce, A.E. \& Beard, J.S. 1995. Dehydration melting of biotite gneiss and quartzamphibolite from 3 to 15 kbar. Journal of Petrology, 36(3): 707-738.

Pitcher, W. S. 1983. Granite type and tectonic environment. In: Hsü, K.J. (Ed.). Mountain Building Processes. New York, Academic Press, p. 19-40.

Philipp, R.P. 1998. A evolução geológica e tectônica do Batólito Pelotas no Rio Grande do Sul. São Paulo, 255p. Tese de Doutorado, Instituto de Geociências, Universidade de São Paulo.

Philipp, R.P., Machado, R., Nardi, L.V.S. \& Lafon, J.M. 2002. O magmatismo granítico Neoproterozóico do Batólito Pelotas no sul do Brasil: novos dados e revisão da geocronologia regional. Revista Brasileira de Geociências, 32(2): 277-290.

Ramos, R. C., Toniolo, J. A., Pinto, L. G. R. \& Koester, E. 2014. Zona de cisalhamento (sutura) de Arroio Grande e o novo Domínio Geofísico Sudeste (Escudo Sul-Rio-Grandense): discussões baseadas em dados geofísicos e de campo. In: Simpósio BRASILEIRO DE GEOFíSICA, VI., 2014, Porto Alegre. Resumos Expandidos. Rio de Janeiro: Sociedade Brasileira de Geofísica.

Ramos, R.C., Koester, E. \& Vieira, D.T. 2020. Sm$\mathrm{Nd}$ systematics of metaultramafic-mafic rocks from the Arroio Grande Ophiolite (Brazil): insights on the evolution of the South Adamastor paleo-ocean. Geoscience Frontiers. 11:2287-2296.
Ramos, R.C., Koester, E., Vieira, D.T., Porcher, C.C., Gezatt, J.N. \& Silveira, R.L. 2018. Insights on the evolution of the Arroio Grande Ophiolite (Dom Feliciano Belt, Brazil) from Rb-Sr and SHRIMP U-Pb isotopic geochemistry. Journal of South American Earth Sciences, 86: 38-53.

Rapp, R.P. \& Watson, E.B. 1995. Dehydration melting of metabasalt at 8-32 kbar: implications for continental growth and crustmantle recycling. Journal of Petrology, 36(4): 891-931.

Saalmann, K., Gerdes, A., Lahaye, Y., Hartmann, L.A., Remus, M.V.D. \& Läufer, A. 2011. Multiple accretion at the eastern margin of the Rio de la Plata craton: the prolonged Brasiliano orogeny in southernmost Brazil. International Journal of Earth Sciences, 100: 355-378.

Siegesmund, S., Basei, M.A.S., Oyhantçabal, P. \& Oriolo, S. 2018. Geology of Southwest Gondwana. Springer, Regional Geology Reviews, 688p.

Silva, L.C., McNaughton, N.J., Armstrong, R., Hartmann, L.A. \& Fletcher, I.R. 2005a. The Neoproterozoic Mantiqueira Province and its African connections: a zircon-based U-Pb geochronologic subdivision for the Brasiliano/ Pan-African systems of orogens. Precambrian Research, 136: 203-240.

Silva, L.C., McNaughton, N.J. \& Fletcher, I.R. 2005b. SHRIMP U-Pb zircon geochronology of Neoproterozoic crustal granitoids (Southern Brazil): A case for discrimination of emplacement and inherited ages. Lithos, 82: 503-525.

Silva, R.F., Dal Olmo-Barbosa, L., Koester, E. \& Vieira, D.T., 2020. Capão do Leão Granite: Highly differentiated garnet-bearing magmatism in the southeastern Dom Feliciano Belt, Brazil. Geological Journal, 56(1): 1- 23.

Silveira, R.L., Koester, E., Rosales, M.J.T., Ramos, R.C., Vieira, D.T., Porcher, C.C., \& Olmo-Barbosa, L.D. 2020. Arcabouço magnetométricogeológico do setor sudeste do Cinturão Dom Feliciano, Rio Grande do Sul, Brasil. Geologia USP. Série Científica, 20(4): 149-167.

Sisson, T.W., Ratajeski, K., Hankins, W.B. \& Glazner, A.F. 2005. Voluminous granitic magmas from common basaltic sources. Contributions to Mineralogy and Petrology, 148(6): 635-661. 
Vieira, D.T., Koester, E. \& Bertotti, A.L., 2016. Petrologia do Granito Chasqueiro, região de Arroio Grande, sudeste do Escudo Sul-RioGrandense. Brazilian Journal of Geology, 46: 79-108.

Vieira, D.T., Koester, E., Ramos, R.C., Porcher, C.C. \& Barbosa, L.D.O., 2019a. Sistema de Zonas de Cisalhamento Transcorrentes Ayrosa Galvão-Arroio Grande, Sudeste do Cinturão Dom Feliciano, RS. In: Simpósıo Nacional DE ESTUdOS TECTÔNICOS, 17, INTERNATIONAL SYMPOSIUM ON TECTONICS, 11TH E SIMPÓSIO Sul-Brasileiro de Geologia, 11., 2019. Bento Gonçalves, Anais..., p. 64.

Vieira, D.T., Koester, E., Ramos, R.C. \& Porcher, C.C., 2019b. Sr-Nd-Hf isotopic constraints and $\mathrm{U}-\mathrm{Pb}$ geochronology of the Arroio Pedrado Gneisses, Dom Feliciano Belt, Brazil: a 680 Ma shoshonitic event in the final stages of the Piratini Arc evolution. Journal of South American Earth Sciences, 95: 102294.

Vieira, D.T., Koester, E., Ramos, R.C., Porcher, C.C. \& Fernandes, L.A.D., 2020. New zircon SHRIMP $\mathrm{U}-\mathrm{Pb}$ ages for the synkinematic magmatism in the Dorsal de Canguçu Transcurrent Shear Zone, Dom Feliciano Belt (Brazil): tectonic implications. Journal of South American Earth Sciences, 100: 102603.
Vieira, D.T., Ramos, R.C., Koester, E., Lenz, C. \& Klein, F.G., 2021. Peraluminous magmatism in the Southernmost Dom Feliciano Belt (Brazil): magmatic evolution process, sources and tectonic implications. Journal of South American Earth Sciences. 106: 103081

Wones D.R. 1989. Significance of the assemblage titanite + magnetite + quartz in granitic rocks. American Mineralogist, 74:744-749.

Zhang, J., Wang, T., Castro, A., Zhang, L., Shi, X., Tong, Y., Zhang, Z., Guo, L., Yang, Q. \& Laccheri, L.M. 2016. Multiple mixing and hybridization from magma source to final emplacement in the Permian Yamatu Pluton, the Northern Alxa Block, China. Journal of Petrology, 57 (5):933980. 